\title{
SIMULATION OF PLANETARY GEARBOX
}

This article is about calculation of planetary gearbox. The gearbox consists of two planetary gears - input and output. The gearbox model is created in Simscape Driveline. The model contains Simscape blocks which represent a gear box, clutch, ideal torque source and many others blocks. At the end we compare our results of simulation with calculations.

Keywords: Simulation, gear, gearbox, gear ratio, Simscape.

\section{Introduction}

Epicyclic gearing or planetary gearing is a gear system consisting of one or more outer gears, or planet gears, revolving about a naseral, or sun gear. Typically, the naser gears are mounted on a movable arm or carrier which itself may rotate relative to the sun gear. Epicyclic gearing systems also incorporate the use of an outer ring gear or annulus, which meshes with the planet gears [1]. Planetary gears (or epicyclic gears) are typically classified as simple or compound planetary gears. Simple planetary gears have one sun, one ring, one carrier, and one planet set. Compound planetary gears involve one or more of the following three types of structures: meshed-planet (there are at least two more planets in mesh with each other in each planet train), stepped-planet (there exists a shaft connection between two planets in each planet train), and multi-stage structures (the system contains two or more planet sets) [2]. Compared to simple planetary gears, compound planetary gears have the advantages of larger reduction ratio, higher torque-to-weight ratio, and more flexible configurations [3]

Advantages:

- Smaller dimension, size as a simple gear

- Easier shifting

- Longer lifetime

- Symmetric distribution of loading

\section{Planetary gear}

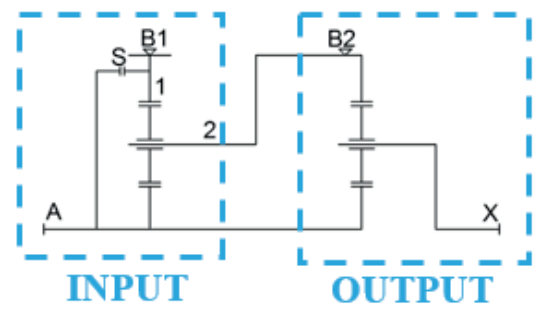

Fig. 1 Kinematic scheme

Kinematic scheme $A 12 / A 2 X$, where:

- input planetary gear: $A 12$

- $\boldsymbol{A}$ is a sun gear,

1 is a ring gear,

2 is a carrier.

- output planetary gear: $A X 2$

$\circ \quad \boldsymbol{A}$ is a sun gear,
$\circ \quad \boldsymbol{X}$ is a carrier,
$\circ \quad 2$ is a ring gear.

- B1, B2-brakes,

- $S$ - clutch. Internal gear ratios for this scheme A12/A2X are:

- Input gear ratio:

- Output gear ratio: Performance:

Required gear ratio:

- $\quad$ mode $=2.25$

- II mode $=3.5$

- $\quad$ III mode $=1$

\footnotetext{
* Maria Tomasikova, Tomas Gajdosik, Michal Lukac, Frantisek Brumercik

Department of Design and Mechanical Element, Faculty of Mechanical Engineering, University of Zilina, Slovakia

E-mail: maria.tomasikova@fstroj.uniza.sk
} 


\section{I mode}

Figure 2 shows power flow for $B 1$ (brake 1) mode. The brake $B 1$ is applied. It means that the ring gear of input planetary gear is stopped. The gear ratio for this mode is 2.25 . The calculated data are in Table 1 [4].

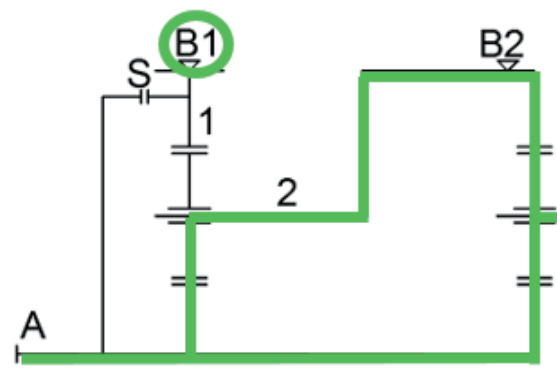

Fig. 2 I mode

Relative angular velocity for I mode Table 1

\begin{tabular}{|l|l|l|}
\hline Relative angular velocity of: \\
\hline sun gear & $\omega_{A}$ & 1 \\
\hline ring gear-brake $B 1$ & $\omega_{1}$ & 0 \\
\hline ring gear-brake $B 2$ & $\omega_{2}$ & 0.224 \\
\hline carrier & $\omega_{X}$ & 0.445 \\
\hline
\end{tabular}

\section{II mode}

Figure 3 shows power flow for $B 2$ (brake 2) mode. The brake $B 2$ is applied. It means that the ring gear of output planetary gear is stopped. The gear ratio for this mode is 3.5. The calculated data are in Table 2 [5].

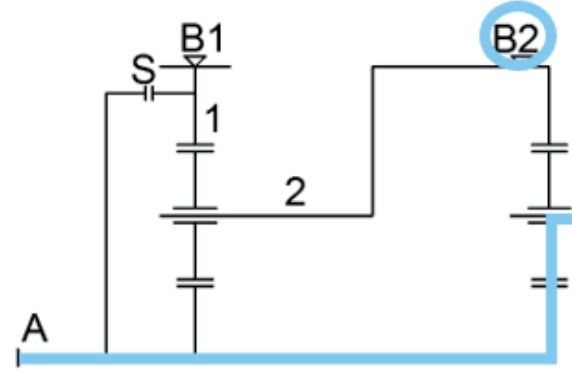

Fig. 3 II mode

Relative angular velocity for II mode Table 2

\begin{tabular}{|l|l|l|}
\hline Relative angular velocity of: \\
\hline sun gear & $\omega_{A}$ & 1 \\
\hline ring gear-brake $B 1$ & $\omega_{1}$ & -0.288 \\
\hline ring gear-brake $B 2$ & $\omega_{2}$ & 0 \\
\hline carrier & $\omega_{X}$ & 0.285 \\
\hline
\end{tabular}

\section{III mode}

Figure 4 shows power flow for $S$ (clutch) mode. The clutch is applied. It means that every element of the gearbox transmits torque. The gear ratio for this mode is 1 . The calculated data are in Table 3 [6].

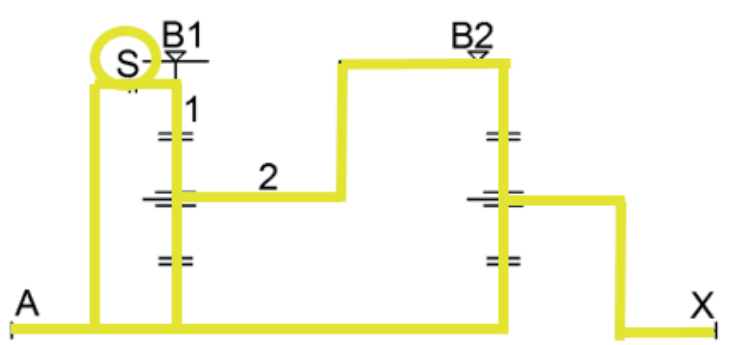

Fig. 4 III mode

Relative angular velocity for III mode

Table 3

\begin{tabular}{|l|l|l|}
\hline \multicolumn{2}{|l|}{ Relative angular velocity of: } \\
\hline sun gear & $\omega_{A}$ & 1 \\
\hline ring gear-brake B1 & $\omega_{1}$ & 1 \\
\hline ring gear-brake B2 & $\omega_{2}$ & 1 \\
\hline carrier & $\omega_{X}$ & 1 \\
\hline
\end{tabular}

The calculation of sun gear velocity:

$\omega_{A}=\frac{2 \cdot \pi \cdot n_{A}}{60}=\frac{2 \cdot \pi \cdot 1250}{60}=130.899[\mathrm{rad} / \mathrm{s}]$

Angular velocities of elements: A, X, 1, 2

Table 4

\begin{tabular}{|c|c|c|c|c|c|}
\hline Element & & $\begin{array}{c}\text { A } \\
\text { (Sun gear } \\
\text { of input } \\
\text { gear) }\end{array}$ & $\begin{array}{c}\text { X } \\
\text { (Carrier } \\
\text { of } \\
\text { output } \\
\text { gear) }\end{array}$ & $\begin{array}{c}1 \\
\text { (Ring } \\
\text { gear of } \\
\text { input } \\
\text { gear) }\end{array}$ & $\begin{array}{c}2 \\
\text { (Carrier } \\
\text { of input } \\
\text { gear) }\end{array}$ \\
\hline Mode & Mechanism & $\omega_{A}$ & $\omega_{X}$ & $\omega_{1}$ & $\omega_{2}$ \\
\hline$I(B 1)$ & & 1 & 0.445 & 0 & 0.224 \\
\hline II (B2) & & 1 & 0.285 & -0.288 & 0 \\
\hline III (S) & & 1 & 1 & 1 & 1 \\
\hline Mode & A21/AX2 & $\begin{array}{c}\omega_{A} \\
{[\mathrm{rad} / \mathrm{s}]}\end{array}$ & $\begin{array}{c}\omega_{X} \\
{[\mathrm{rad} / \mathrm{s}]}\end{array}$ & $\begin{array}{c}\omega_{1} \\
{[\mathrm{rad} / \mathrm{s}]}\end{array}$ & $\begin{array}{c}\omega_{2} \\
{[\mathrm{rad} / \mathrm{s}]}\end{array}$ \\
\hline$I(B 1)$ & & 130.899 & 58.250 & 0 & 29.321 \\
\hline$I I(B 2)$ & & 130.899 & 37.306 & -37.698 & 0 \\
\hline III (S) & & 130.899 & 130.899 & 130.899 & 130.899 \\
\hline
\end{tabular}


Speeds of elements: A,X,1,2

\begin{tabular}{|c|c|c|c|c|}
\hline Mode & $\begin{array}{l}n_{A} \\
{\left[s^{1}\right]}\end{array}$ & $\begin{array}{l}\boldsymbol{n}_{X} \\
{\left[\mathbf{s}^{-1}\right]}\end{array}$ & $\begin{array}{l}n_{1} \\
{\left[s^{1}\right]}\end{array}$ & \begin{tabular}{|l}
$n_{2}$ \\
{$\left[s^{-1}\right]$}
\end{tabular} \\
\hline$I(B 1)$ & 20.833 & 9.271 & 0 & 4.666 \\
\hline$I I(B 2)$ & 20.833 & 5.937 & -6 & 0 \\
\hline III $(S)$ & 20.833 & 20.833 & 20.833 & 20.833 \\
\hline
\end{tabular}

\section{Simulation of gear model in Simscape Driveline}

Simscape Driveline ${ }^{\mathrm{TM}}$ (formerly SimDriveline ${ }^{\mathrm{TM}}$ ) provides component libraries for modeling and simulating rotational and translational mechanical systems. It includes models of worm gears, lead screws, and vehicle components such as engines, tires, transmissions, and torque converters [7]. You can use these components to model the transmission of mechanical power in helicopter drivetrains, industrial machinery, automotive powertrains, and other applications. You can integrate electrical, hydraulic, pneumatic, and other physical systems into your model using components from the Simscape ${ }^{\mathrm{TM}}$ family of products [8].

The gear model (Fig. 5) is created in Simscape Driveline. The gearbox consists of two planetary gear blocks. Each of these planetary gear blocks has a gear ratio. The disk friction clutch is used as brakes $(B 1, B 2)$ and clutch $(S)$. These blocks are set by kinematic scheme (Fig. 1) [9]. These blocks are aligned and placed according to kinematic scheme (Fig. 1) [9].

The model is made as a parametric model. We can change input parameters as performance, gear ratios as far as the
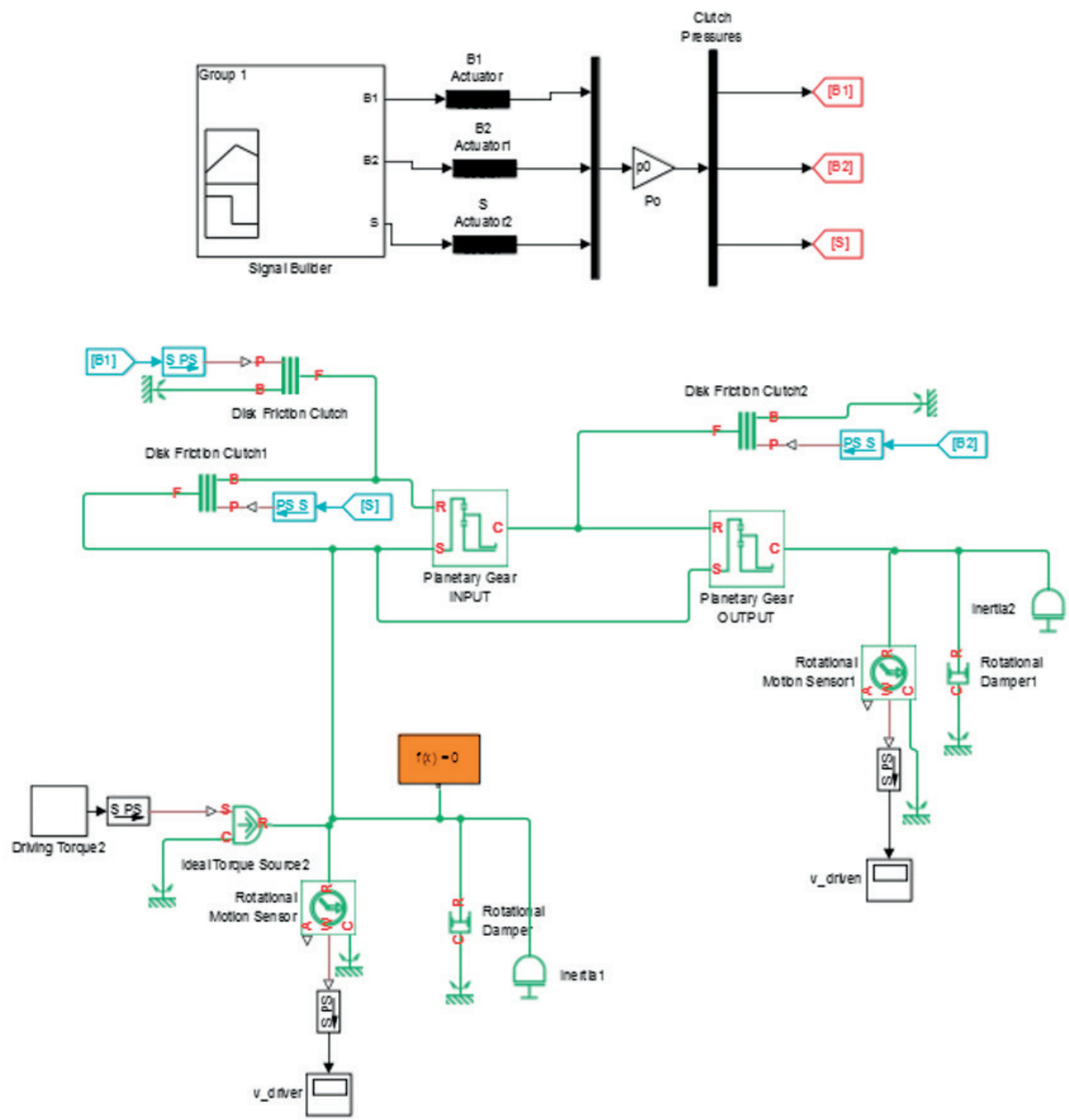

Fig. 5 Gearbox model 
kinematic scheme is the same. The model contains many other blocks as an ideal torque source, rotational motion sensors, rotational dampers, inertias, scopes.

\section{Simscape block - Planetary gear}

This block (Fig. 6) models a gear train with sun, planet, and ring gears. Planetary gears are common in transmission systems, where they provide high gear ratios in compact geometries.

A carrier connected to a drive shaft holds the planet gears. Ports $C, R$, and $S$ (Table 6) represent the shafts connected to the planet gear carrier, ring gear, and sun gear [10].

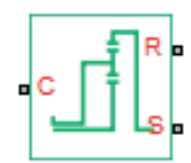

Fig. 6 Planetary gear block

Ports of block

Table 6

\begin{tabular}{|l|l|}
\hline$C$ & Rotational conserving port that represents the planet gear carrier \\
\hline $\boldsymbol{R}$ & Rotational conserving port that represents the ring gear \\
\hline $\boldsymbol{S}$ & Rotational conserving port that represents the sun gear \\
\hline $\boldsymbol{H}$ & Thermal conserving port for thermal modeling \\
\hline
\end{tabular}

\section{Gearbox modes}
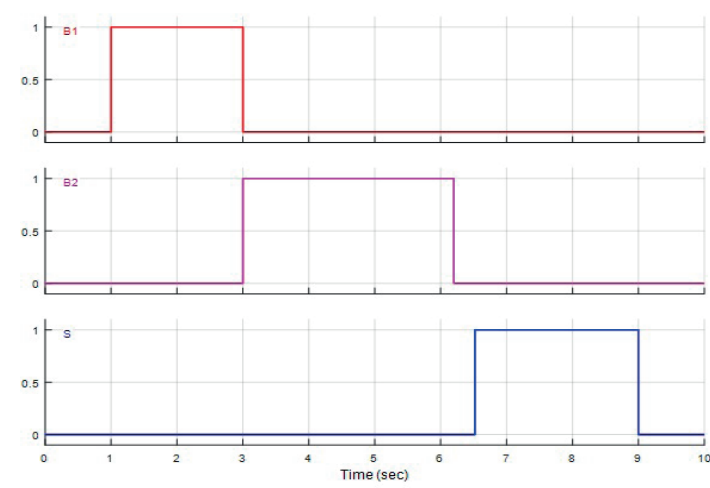

Fig. 7 Signal builder

The different modes $(B 1=I, B 2=I I, S=I I I)$ are triggered by Signal builder. Simulation time is 10 seconds. Figure 7 shows a time schedule of modes.

\section{The simulation results}

The simulation used solver- ode $15 \mathrm{~s}$. This is one of many solvers, which can be used for simulation in Driveline [11].

It computes the model's state at the next time step using variable-order numerical differentiation formulas (NDFs). These

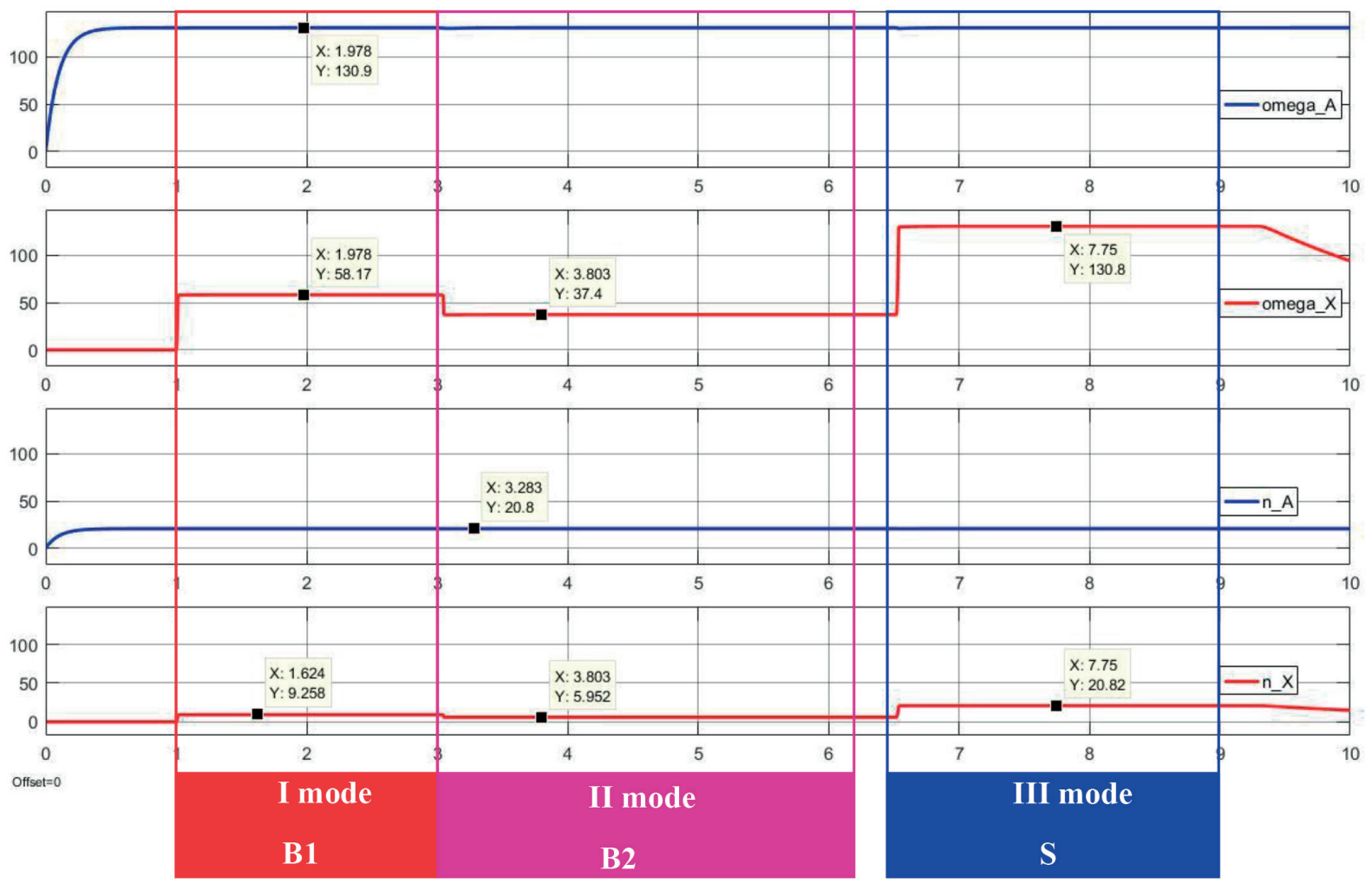

Fig. 8 Simulation results 


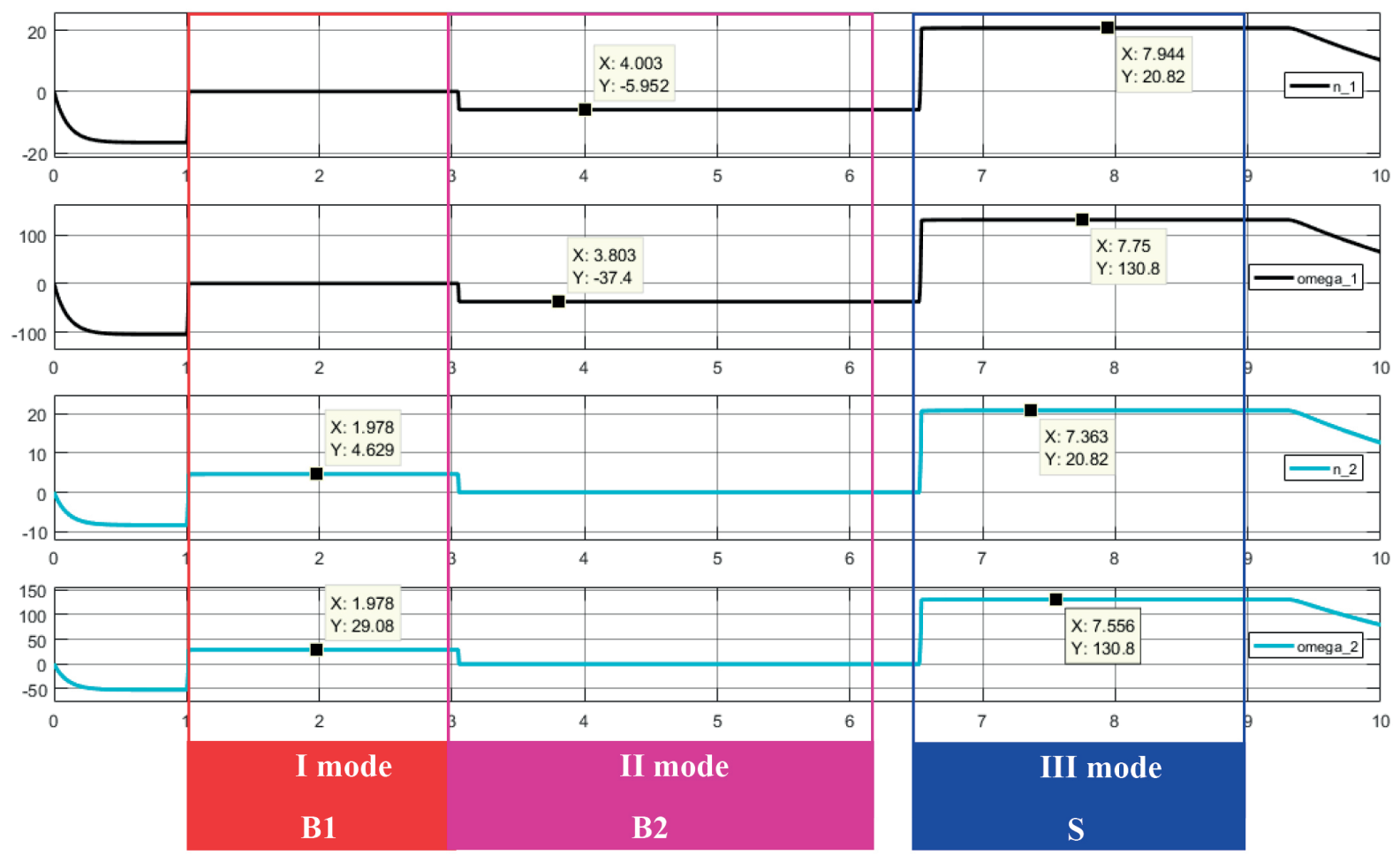

Fig. 9 Simulation results

are related to, but more efficient than the backward differentiation formulas (BDFs), also known as Gear's method [12].

In following Figs. 8 and 9 are shown simulation results. We can see that $\mathrm{Y}$ - coordinates of point are the values of the angular velocity for $A, X, 1,2$ elements.

\section{Conclusion}

This article describes how the gearbox model in Simscape Driveline can be made. If we know input parameters, we can simulate how the gearbox works. The gearbox is created by Simscape block. The simulation is divided into 3 parts. Each part represents one of 3 gearbox modes. The change of modes is set by a signal builder. We measured output parameters and also angular velocity of gearbox elements as carriers and ring gears. If we compare the simulation results and values which we get from the calculation (Tables 4 and 5), we can see that the simulation ran well.

\section{Acknowledgments}

This paper presents results of work supported by the Slovak Scientific Grant Agency of the Slovak Republic under the project No. VEGA 1/0077/15.

The research is supported by the following institutions: Slovak Research and Development Agency under the contract No. APVV-14-0508 - Development of new methods for the design of special large-size slewing rings.

\section{References}

[1] DROZDZIEL, P., KRZYWONOS, L.: The Estimation of the Reliability of the First Daily Diesel Engine Start-up During its Operation in the Vehicle. Eksploatacja i Niezawodnosc - Maintenance and Reliability, 1(41), 2009, 4-10.

[2] GLOWACZ, A.: Diagnostics of DC and Induction Motors Based on the Analysis of Acoustic Signals. Measurement Science Review, vol. 14, No. 5, 2014, 257-262.

[3] KOHAR, R., HRCEK, S.: Dynamic Analysis of a Rolling Bearing Cage with Respect to the Elastic Properties of the Cage for the Axial and Radial Load Cases. Communications - Scientific Letters of the University of Zilina, vol. 16, No. 3A, 2014, 74-81. 
[4] HRCEK, S., KOHAR, R., MEDVECKY, S.: Determination on the Maximum Roller Bearing Load with Regards to Durability thereof using FEM Analysis. Communications - Scientific Letters of the University of Zilina, vol. 14, No. 3, 2012, 55-61.

[5] DROZDZIEL, P., KOMSTA, H., KRZYWONOS, L.: Repair Costs and the Intensity of Vehicle Use. Transport Problems, vol. 8, No. 3, 2013, 131-138.

[6] KOHAR, R., HRCEK, S., MEDVECKY, S.: Usage of Dynamic Analysis to Determine Force Interactions between Components of Rolling Bearings. Communications - Scientific Letters of the University of Zilina, vol. 14, No. 3, 2012, 62-67.

[7] KOMSTA, H., BRUMERCIKOVA, E., BUKOVA, B.: Applications of NFC Technology in Passenger Rail Transport. Transport Problems, vol. 11, No. 3, 2016, pp. 43-53.

[8] CABAN, J., DROZDZIEL, P., BARTA, D., LISCAK, S.: Vehicle Tire Pressure Monitoring Systems, Diagnostyka, vol. 15, No. 3, 2014, ISSN 1641-6414.

[9] Matlab reference, 1994-2016 The MathWorks, Inc.

[10] CABAN J., MARCZUK A., SARKAN B., VRABEL J.: Studies on Operational Wear of Glycol-Based Brake Fluid. Przemyst Chemiczny, vol. 94, No. 10, 2015, 1802-1806.

[11] BRUMERCIKOVA, E., BUKOVA, B., KRZYWONOS, L.: NFC Technology in Public Transport. Communications - Scientific Letters of the University of Zilina, vol. 18, No. 2, 2016, 20-25.

[12] BUKOVA, B., BRUMERCIKOVA, E., KONDEK, P., SOJCAK, D.: The Impact of International Entrepreneurship on the Development of Transport. Communications - Scientific Letters of the University of Zilina, vol. 18, No. 2, 2016, 139-142. 